\title{
Michael addition-initiated sequential reactions from 1,3- dicarbonyls for the synthesis of polycyclic heterocycles
}

Xavier Bugaut,* Damien Bonne, Yoann Coquerel, Jean Rodriguez and Thierry Constantieux* Aix Marseille Université, CNRS, iSm2 UMR 7313

13397, Marseille, France

Telephone: 33-(0)491-282-874

Fax: 33-(0)491-289-187

e-mail: thierry.constantieux@univ-amu.fr; xavier.bugaut@univ-amu.fr 


\begin{abstract}
This review aims to highlight the most significant recent developments on synthetic strategies involving consecutive, domino and multicomponent reactions featuring a Michael addition-initiating step for the synthesis of polycyclic heterocycles from 1,3-dicarbonyls. These original sequences constitute more efficient and eco-compatible alternatives to known synthetic approaches to heterocyclic compounds allowing for an even faster and highly desirable generation of molecular diversity and complexity.
\end{abstract}

Keywords: Consecutive reactions. Domino reactions. Multicomponent reactions. Michael addition. Polycyclic heterocycles. 1,3-Dicarbonyl compounds. 


\section{1.- INTRODUCTION}

The field of heterocyclic chemistry is one of the most explored branches of organic chemistry, due to the large implication of heterocycles in synthetic, biological, pharmaceutical as well as material sciences. As a consequence, the development of efficient and selective methodologies to access focused libraries of functionalized heterocyclic building blocks is of primary importance, and still constitutes an intensively explored area of investigation. In order to address the contemporary economic and ecological issues, these methodologies should combine the classical criteria of efficiency, selectivity and molecular diversity with sustainability criteria such as waste production, toxicity and hazard of chemicals and protocols, and energy requirements. Among the numerous synthetic tools at the chemist's disposal, domino (DRs)[1] and/or multicomponent (MCRs)[2] reactions are particularly well adapted with respect to these modern criteria, especially when they are conducted in water[3] or unconventional solvents.[4] By using readily available and simple substrates, by limiting the number of chemical operations and by maximizing the atom economy, these transformations are particularly suitable for combinatorial and diversity-oriented synthesis.[5] DRs and MCRs have been intensively applied to the synthesis of heterocycles,[6] and proved also to be efficient for total synthesis purpose,[7] since asymmetric versions are now well mastered.[8] Among the large variety of substrates that may be involved in domino and multicomponent reactions, 1,3-dicarbonyls (1,3-diCOs) are particularly suitable due to their multiple nucleophilic and electrophilic potential reactive sites. For more than 15 years, our group has studied the specific reactivity of these substrates through the development of new DRs and MCRs-based methodologies for the synthesis of different families of highly functionalized small organic molecules, including heterocycles.[9] More precisely, we are particularly interested in Michael addition-initiated sequences involving 1,3-diCOs[10] as 
pronucleophiles for the development of methodologies allowing the creation of high molecular complexity from simple substrates. This is the topic this minireview will focus on, through the description of selected recent examples leading to the formation of elaborated polycyclic heterocycles.

\section{1 - DRs and MCRs involving a cyclization on an iminium ion in the racemic series}

By definition, DRs and MCRs result in the formation of several new bonds in a one-pot process, making them especially suitable tools for the rapid construction of polycyclic structures. Most of the examples present in the literature are based on the same principle: after an initial Michael addition of a 1,3-dicarbonyl substrate to an $\alpha, \beta$-unsaturated compound, an iminium ion is formed and then trapped by a nucleophile. Different arrangements of these structural elements in the two or three reaction partners can lead to a large variety of heteropolycyclic products.

The first example of a consecutive sequence involving three components, initiated by a Michael addition that resulted in the formation of a bicyclic structure was reported in 1979 by the group of Eschenmoser during their study of an approach to macrolides.[11] This area of investigation remained unexplored until our group published in 2001 the first Michael addition-initiated domino three-component reaction between a $\beta$-ketoester $\mathbf{1}$, an $\alpha, \beta$ unsaturated aldehyde or ketone $\mathbf{2}$ and a primary amine functionalized with a tethered nucleophile (amine, alcohol or thiol) 3 (Scheme 1).[12] The combination of these three substrates in refluxing toluene in the presence of $4 \AA$ molecular sieves as the sole reaction promoter resulted in the formation of the heteropolycyclic structure 4 . 


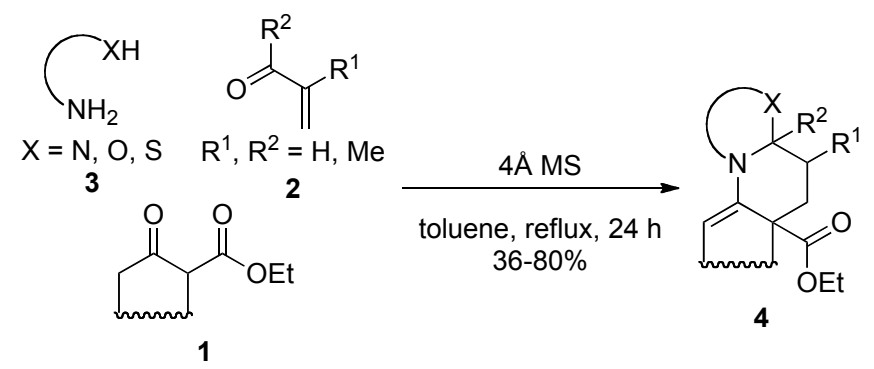

\section{Scheme 1}

Sequential reactions with the same substrates showed that the Michael addition was indeed the initiating step of the cascade, the enaminoester $\mathbf{5}$ obtained from the amine and the $\beta$-ketoester being inert under the reaction conditions (Scheme 2).

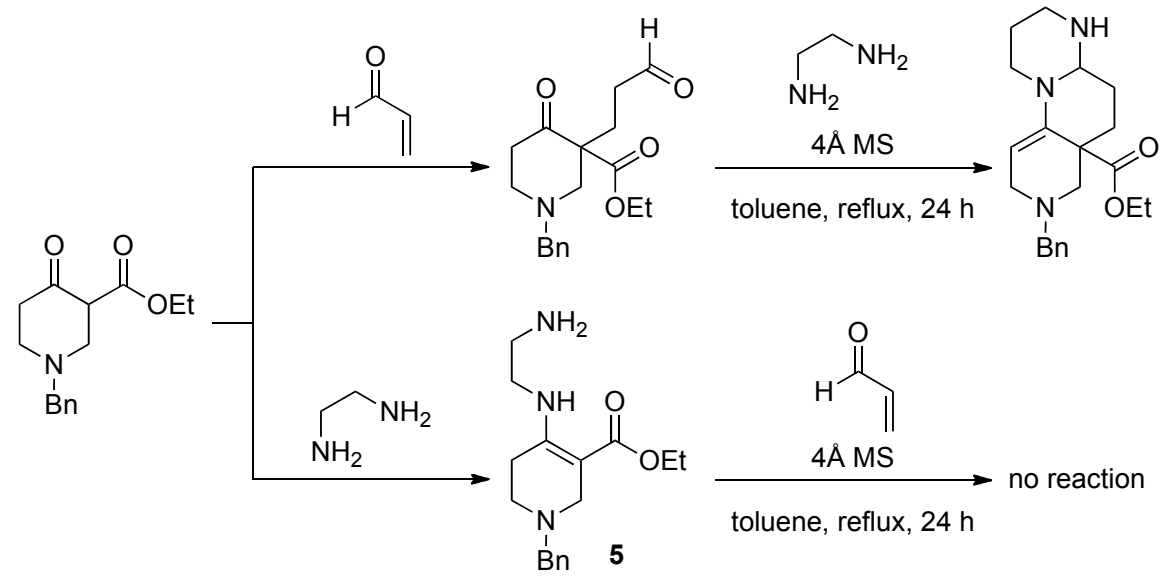

\section{Scheme 2}

Subsequently related transformations were described exploiting different functionalized amines, which resulted in the formation of various polyheterocyclic products (Table 1). For example, phenylalaninol can be incorporated to obtain tetrahydropyridines $\mathbf{6}$ with moderate diastereoselectivities (Entry 1, 2:1 dr).[13] Aromatic functionalized amines are also suitable starting materials. When $o$-phenylenediamine was used, the product underwent spontaneous aerobic in-situ oxidation to produce fused benzimidazoles 7 (Entries 2 and 3).[14] Noteworthy the use of 2-aminophenol as the bis-nucleophile triggered a change in the regioselectivity of the last cyclization, which resulted in the formation of a spirocyclic type aminal 8 (Entry 4).[12] Finally, when two nucleophilic functions are present on the amine 
substrate, the complex polycyclic product 9 containing two aminal motifs was formed as only two diastereomers in a 2.3:1 ratio (Entry 5).[12]

Table 1. Reactions between $\beta$-ketoesters or $\beta$-diketones, $\alpha, \beta$-unsaturated aldehydes and functionalized primary amines

Entry


Replacing $\beta$-ketoesters with $\beta$-ketoamides $\mathbf{1 0}$ that possess one more nucleophilic position on the amide nitrogen atom allowed to attain a further level of complexity in these transformations. We showed that this slight modification of the substrate led to the synthesis of the original 2,6-diazabicyclo[2.2.2] octane (2,6-DABCO) core 11 (Scheme 3).[15] During this process, not less than five new bonds and three stereogenic centers were created, and the 2,6-DABCOs were obtained as single diastereomers in good to excellent yields. Both $\alpha$-unsubstituted and cyclic secondary $\beta$-ketoamides were suitable substrates and a variety of functionalized primary amines, including aliphatic diamines and amino alcohols along with 2aminophenol, were tolerated.

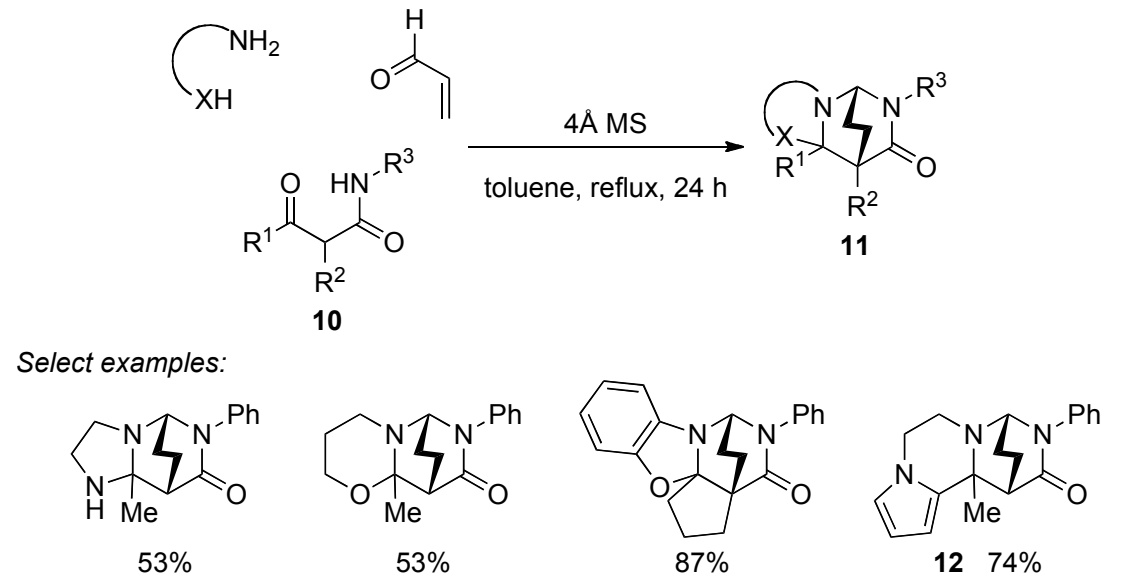

Scheme 3

The combination of multicomponent reactions with green reusable solvents is a promising research area towards sustainable development in organic synthesis.[4] The above synthesis of 2,6-DABCOs was shown to perform efficiently in ionic liquids, namely $[\mathrm{bmin}]\left[\mathrm{BF}_{4}\right]$ and $[\mathrm{bmin}]\left[\mathrm{NTf}_{2}\right] .[16]$ In these green media, not only the use of molecular sieves could be omitted and better yields obtained than in toluene, but it also expanded the scope of the reaction allowing the use of $\beta$-substituted $\alpha, \beta$-unsaturated aldehydes. Recyclability of the ionic liquids in this process was also demonstrated. 
The replacement of the nucleophilic heteroatomic moiety on the functionalized primary amine by an electron-rich aromatic ring allowed the design of Michael addition/iminium formation/Pictet-Spengler cascade cyclization sequences, where a $\mathrm{C}-\mathrm{C}$ bond formation takes place instead of the final aminal cyclization. An example of this reactivity was reported in the aforementioned synthesis of 2,6-DABCOs, with 1-(2-aminoethyl)pyrrole (13) as starting material, affording the product 12 (Scheme 3).[15] We then further extended the use of this $N$-substituted pyrrole in multicomponent reactions with $\beta$-diketones and $\beta$-ketoesters (Scheme 4).[17] With $\alpha$-unsubstituted acyclic 1,3-DiCOs, pyrrolopiperazines 14 were formed, while the corresponding cyclic derivatives resulted in the stereoselective formation of the aza-steroid type scaffolds 15.

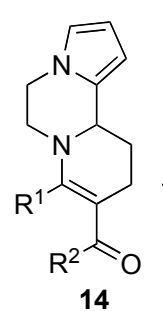

14

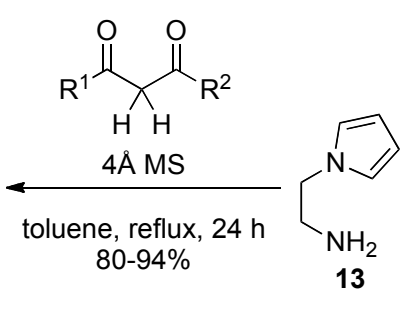

13

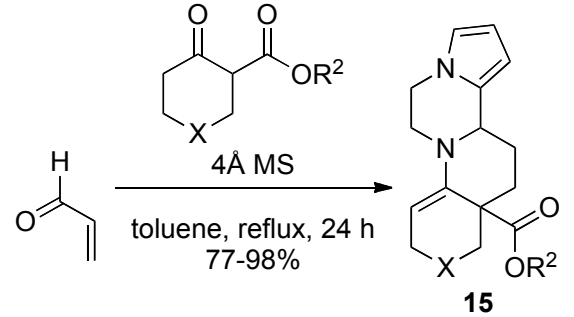

15

\section{Scheme 4}

Soon after, Dixon and coworkers showed that $\beta$-ketoamides bearing a variety of $\pi$ nucleophiles 16 were amenable to this kind of processes (Scheme 5).[18] A combination of two heterogeneous catalysts was used to prevent their mutual deactivation. The basic supported phosphazene P-BEMP promoted the Michael addition[19] and the acidic resin Amberlyst A15 triggered the Pictet-Spengler cyclization. The polycyclic products 17 were obtained in good yields with moderate diastereoselectivities. The electron-rich $\pi$-nucleophile could also be part of the Michael acceptor starting material.[20] 


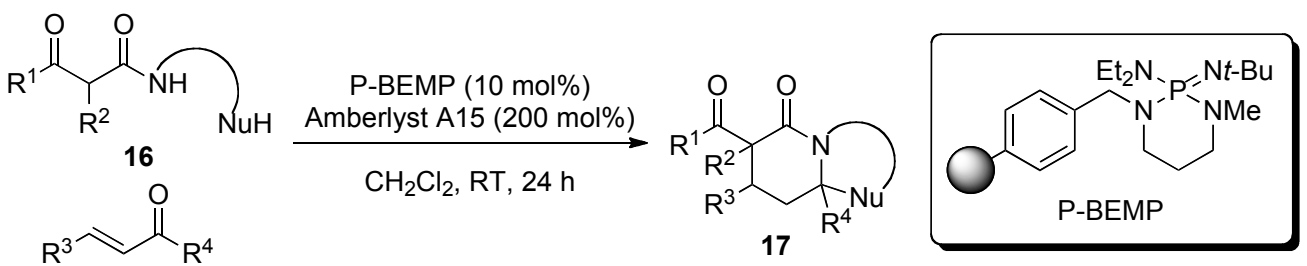

Select examples:
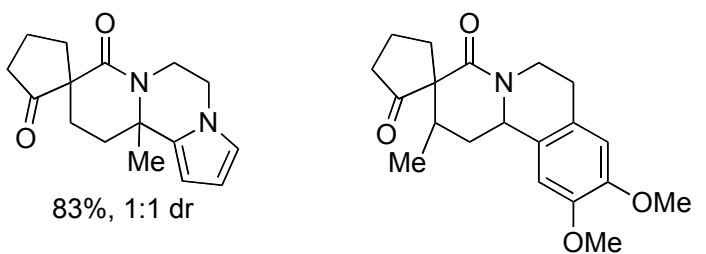

$85 \%, 7: 5: 5: 3 \mathrm{dr}$

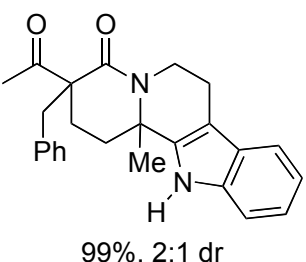

Scheme 5

\section{2 - Organocatalytic enantioselective sequential transformations involving a cyclization on an iminium ion}

In 2009, the group of Franzén reported the first organocatalyzed enantioselective cascade involving a Michael addition/iminium formation/Pictet-Spengler cyclization sequence (Scheme 6).[21] (S)-Diphenyl prolinol trimethylsilyl ether $\mathbf{1 8}$ proved to be an efficient catalyst for the enantioselective Michael addition of $\beta$-carbamoylesters 19 on cinnamaldehyde derivatives 20. After its completion, the products $\mathbf{2 1}$ were formed by the addition of $\mathrm{HCl}$ at low temperature to catalyze a moderately diastereoselective PictetSpengler cyclization. This consecutive procedure allowed the synthesis of both indolo[2,3a]quinolizidines and benzo[ $[a]$ quinolizidines. 


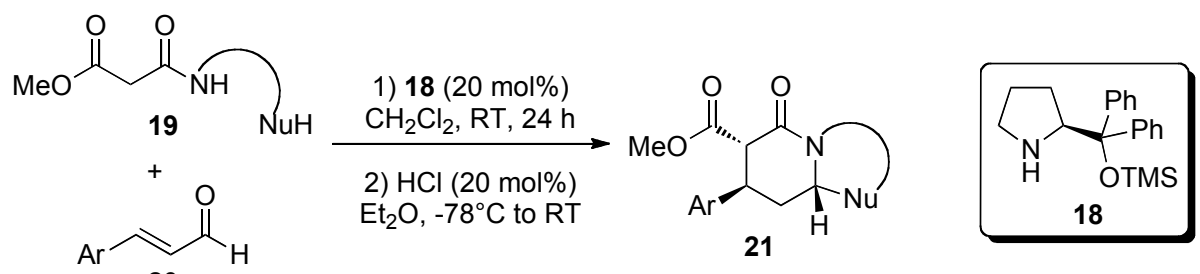

Select examples:

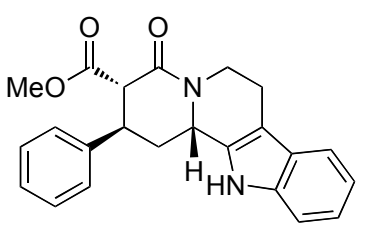

$69 \%, 85: 15 \mathrm{dr}, 94 \%$ ee

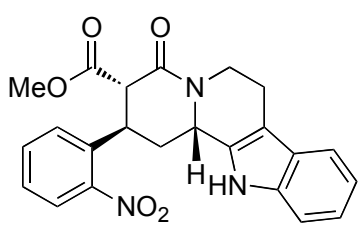

$53 \%, 90: 10$ dr, $95 \%$ ee

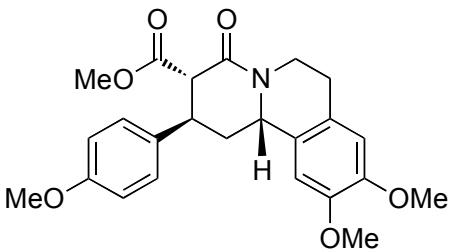

$71 \%, 76: 24 \mathrm{dr}, 89 \%$ ee

Scheme 6

The same authors then extended their methodology to a larger variety of electron-rich aromatic rings including benzofurans, furans and thiophenes.[22] However, only traces of product were obtained with pyrrole because of competing pathways. For each case, the choice of the appropriate reaction conditions used in the Pictet-Spengler cyclization allowed the synthesis of either the kinetic $\mathbf{2 2}$ or the thermodynamic diastereomer $\mathbf{2 3}$ with moderate to good stereoselectivities (Scheme 7). $\beta$-Ketoamides were also competent nucleophiles in this reaction[23] and this strategy was applied to the total syntheses of several members of the corynantheine and ipecac alkaloid families.[24]

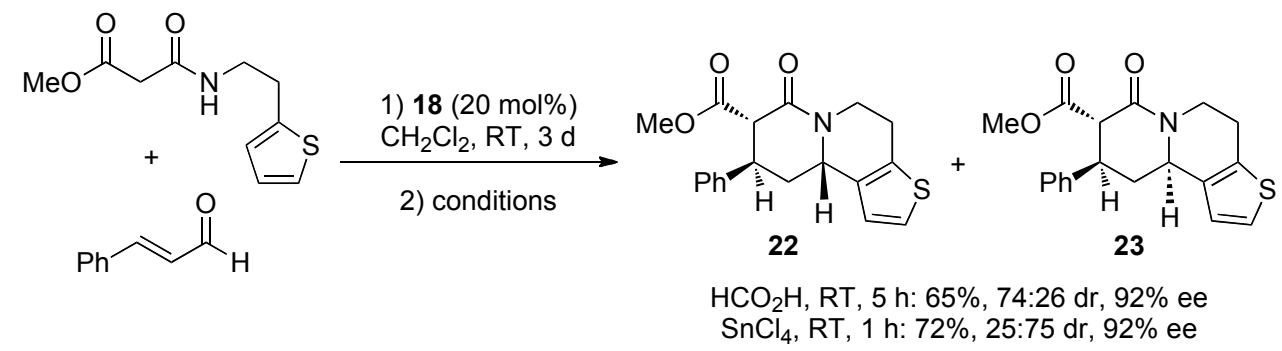

Scheme 7

The next step was to design a sequential reaction involving three components, i. e. a $\beta$-ketoester, an $\alpha, \beta$-unsaturated aldehyde and a tryptamine derivative $\mathbf{2 5}$ as external bisnucleophile for the transamination/Pictet-Spengler sequence promoted by an excess of 
benzoic acid (Scheme 8).[25] An advantage of this strategy over the previous one is that all starting materials are easily available.

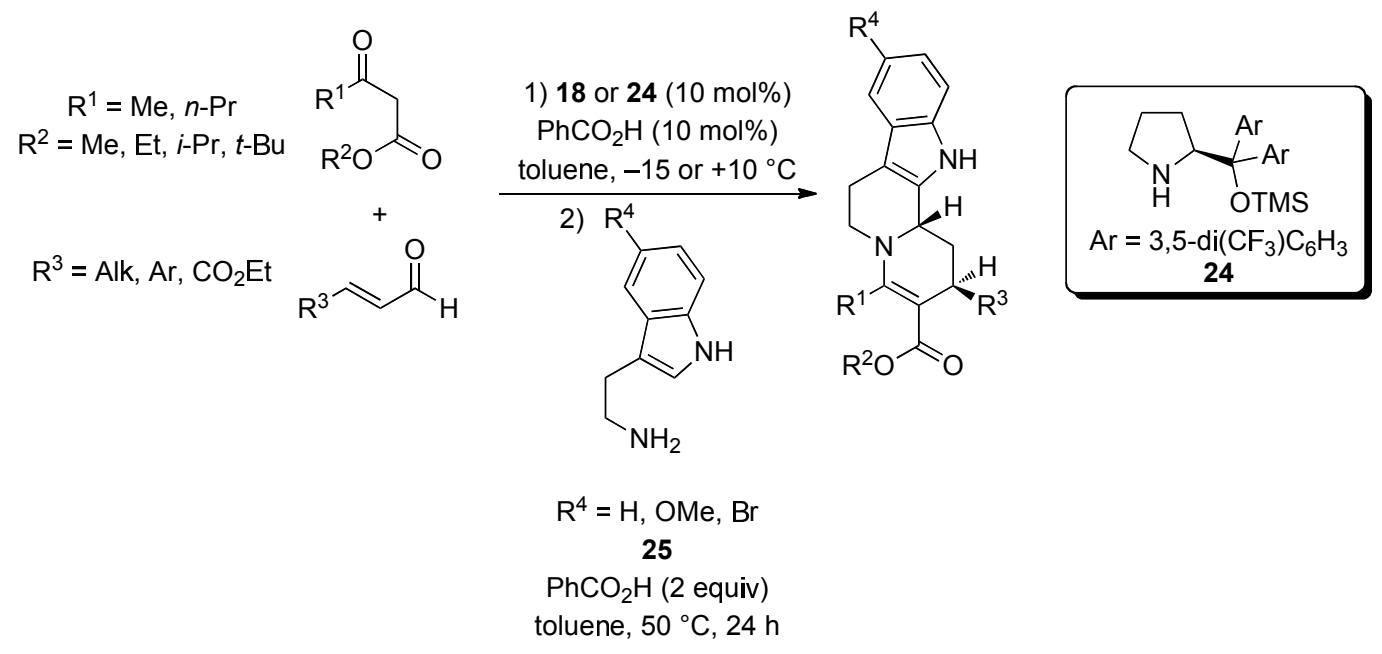

\section{Scheme 8}

The importance of a fine tuning of the acidic conditions was again recently illustrated in related diastereoselective Pictet-Spengler cyclizations.[26] Similar transformations with cyclic diketones pronucleophiles were also reported[27,28] and the strategy could be applied to a straightforward route towards the total synthesis of secologanine tryptamine and dopamine alkaloids.[29]

In 2011, the group of Ye reported an interesting variation of the bimolecular cascade developed by Franzén. For that purpose, $\beta$-carbamoylesters 26 were designed, in which the $\pi$-nucleophile is replaced by a benzylic alcohol, substituting the final Pictet-Spengler reaction by the formation of an aminal (Scheme 9).[30] Noteworthy $\alpha, \beta$-unsaturated ketones 27 were competent electrophiles in the Michael addition, provided that a bifunctional organocatalyst containing both a thiourea and a primary amine was used. After optimization of the reaction conditions, catalyst $\mathbf{2 8}$ was found excellent to control the enantioselectivity of the Michael addition, albeit at the cost of very long reaction times. Once again, the addition of an acid was needed to effect the last cyclization and afford a series of dihydro-1,3-oxazines 29 that contain a tetrasubstituted center with high yields, enantio- and diastereoselectivities. One 
further example was described, in which the benzylic alcohol was replaced by a phenol to deliver the corresponding 1,3-oxazolidine with moderate enantioselectivity.

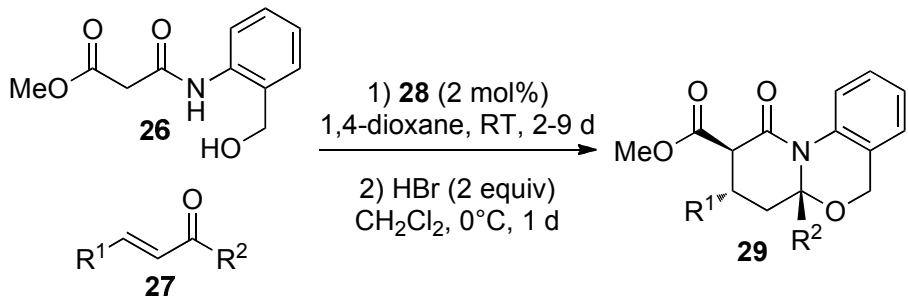

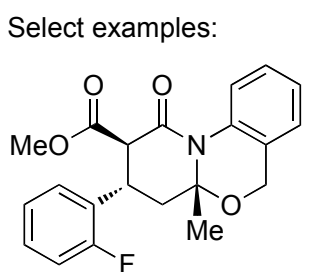

$85 \%, 9: 1 \mathrm{dr}, 97 \%$ ee<smiles>CC[C@@]12Cc3ccccc3N(C)[C@](CC)(CO1)C(=O)C2C(=O)OC</smiles>

$96 \%, 8: 1 \mathrm{dr}, 90 \%$ ee

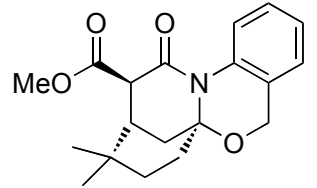

$26 \%,>20: 1 \mathrm{dr}, 95 \%$ ee

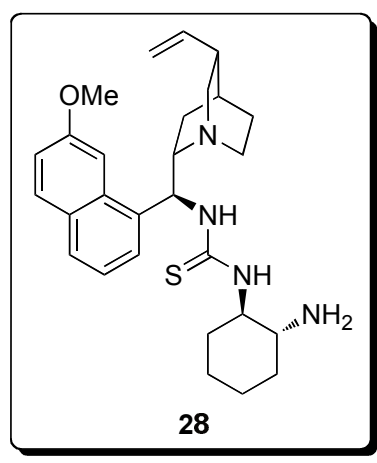

Scheme 9

Shortly after, the same group studied the scope of this transformation by using $\alpha, \beta-$ unsaturated aldehydes as Michael acceptors, $(R)$-diphenyl prolinol trimethylsilyl ether (ent18) as the catalyst of choice and different nucleophilic functionalities: phenols afforded 1,3oxazolidines $\mathbf{3 0}$ (.

Table 2, Entry 1)[31] whereas benzylic alcohols gave an access to dihydro-1,3-oxazines 31 (Entry 2).[32] Surprisingly enough, primary carboxamide-containing substrates delivered dihydrooxazinone 32 instead of the expected dihydroquinazolinones (Entry 3).[32] It is assumed that the carboxamide is hydrolyzed to the carboxylic acid in the presence of $\mathrm{TsOH}$ before the cyclization.

Table 2. Reactions between functionalized secondary $\beta$-carbamoylesters and $\alpha, \beta$ unsaturated aldehydes 


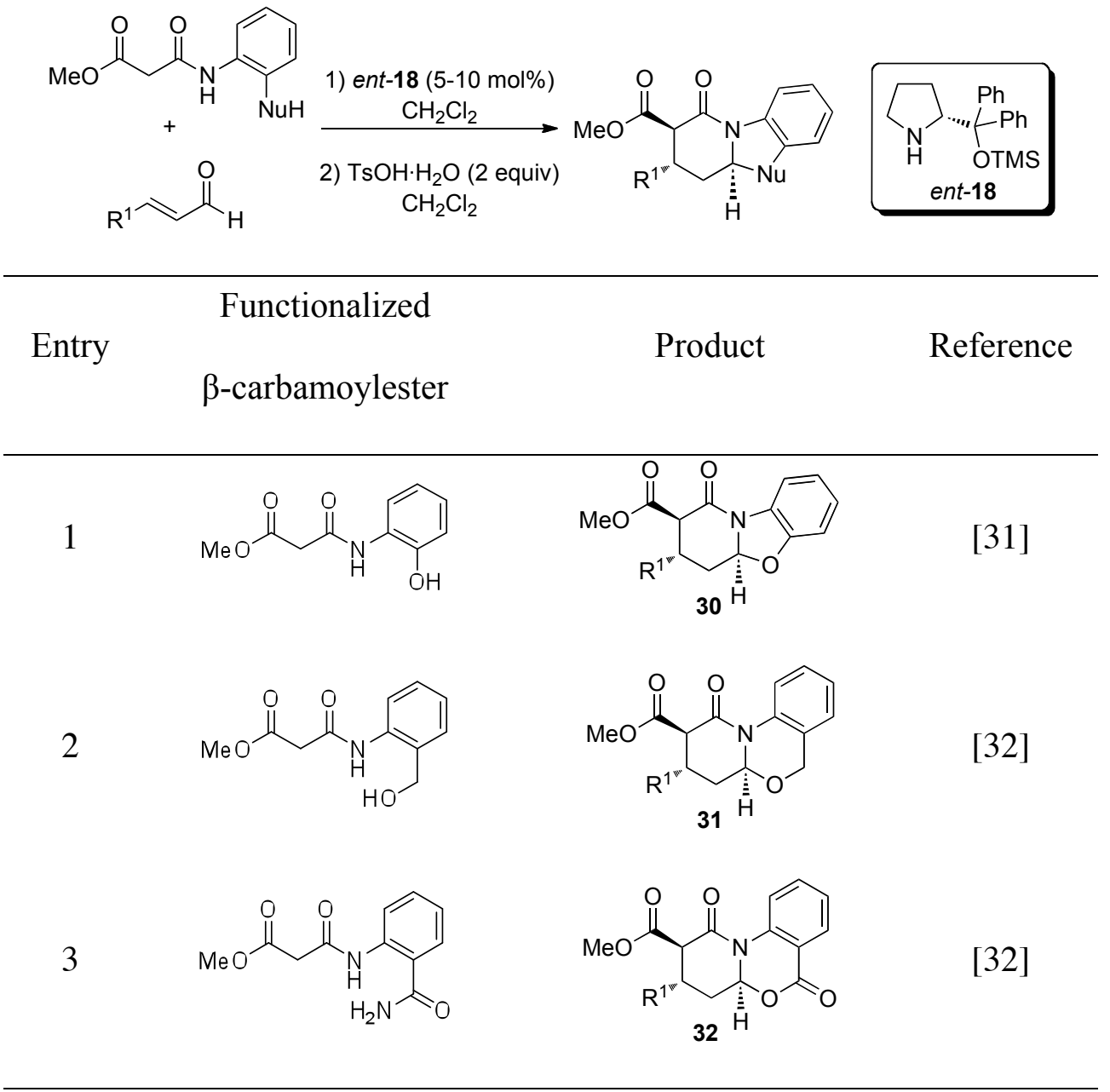

Finally, two preliminary examples of the corresponding trimolecular sequential couplings have also been described (Scheme 10).[27] After an enantioselective Michael addition between cyclohexane-1,3-dione and aliphatic $\alpha, \beta$-unsaturated aldehydes catalyzed by (S)-diphenylprolinol trimethylsilyl ether 18, the addition of either 2-aminobenzylamine $\mathbf{3 3}$ or anthranilamide $\mathbf{3 4}$ in the presence of acetic acid, respectively produced pyridoquinazoline $\mathbf{3 5}$ and pyridoquinazolinone 36 with high enantioselectivities. 


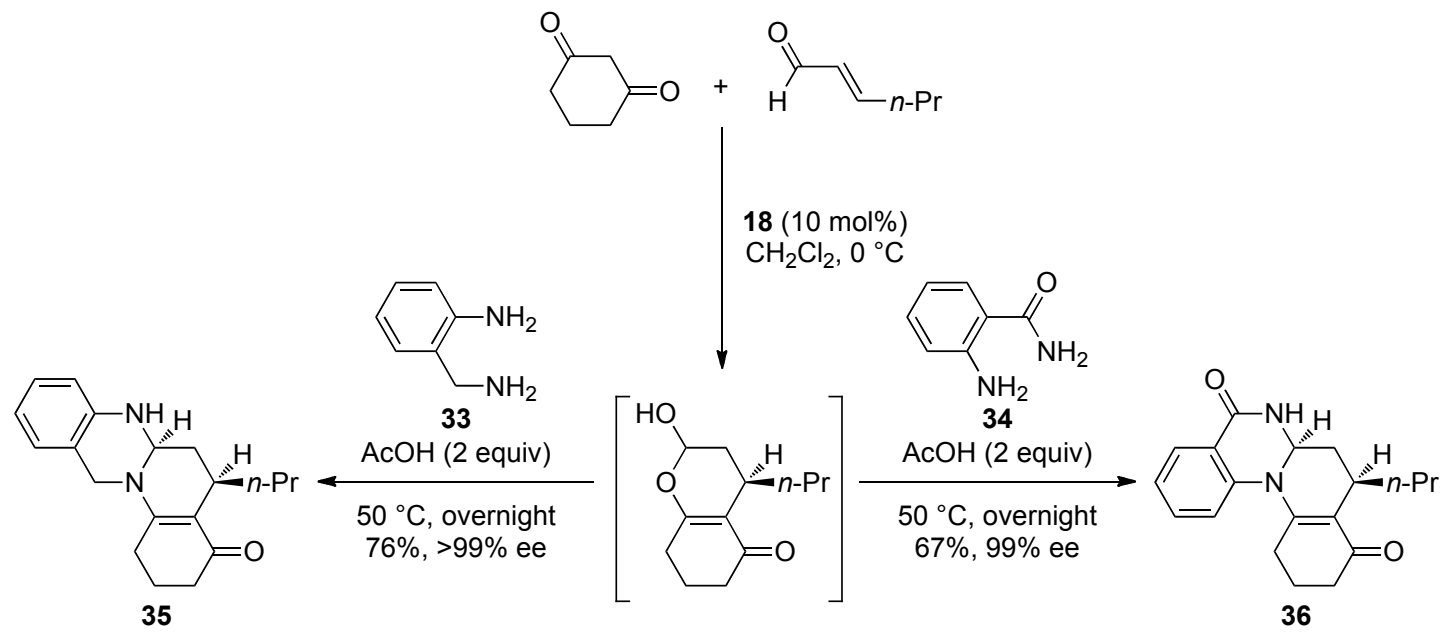

Scheme 10

Despite the development of several strategies for the construction of polycyclic heterocycles by enantioselective organocatalytic domino and sequential reactions initiated by the Michael addition of a 1,3-dicarbonyl, it is worth noting that no multicomponent variant of these transformations has been reported to date. Further developments in this direction are expected in the near future.

\section{3 - Miscellaneous transformations}

When performed intramolecularly, the Michael addition/hemiacetalization sequence can lead to the concomitant formation of two rings. This strategy was used by Watanabe and coworkers to synthesize a series of natural products including (-)-mellein and (+)ramulosin.[33] Besides this, when bis-Michael acceptors 37 were used, two molecules of 1,3dicarbonyl could be condensed with it under Lewis-acid catalysis to afford spirocyclic compounds 38 (Scheme 11).[34] 


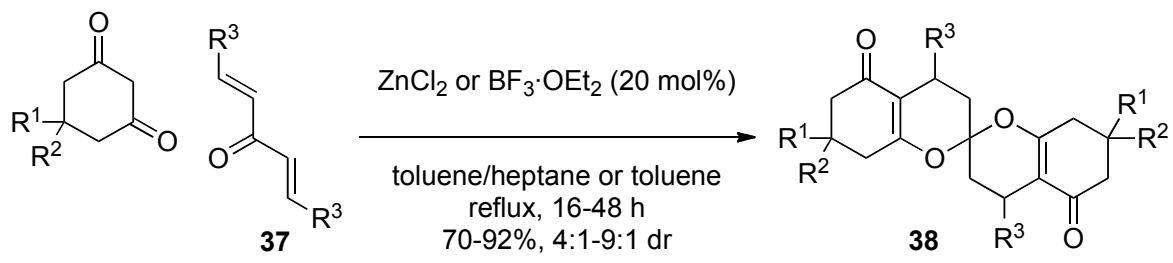

Scheme 11

To finish with, a different strategy to prepare polycyclic structure is to combine at least two Michael acceptors in a cascade consisting of several chemoselective Michael additions. The properties of the substrates have to be finely tuned so that a preferred sequence leads to the formation of one major product. Many carbocycles were prepared by this strategy but only one publication related to the formation of heterocycles can be found in the literature (Scheme 11).[35] The combination of curcumins 39 with isatylidene malonitriles $\mathbf{4 0}$ in the presence of a catalytic amount of $N, N$-dimethylaminopyridine (DMAP) in EtOH afforded tetracyclic spirooxindoles $\mathbf{4 1}$ in excellent yields and diastereoselectivities through a four-step sequence: Michael addition of curcumins on the isatylidene malonitrile $\mathbf{4 0}$, followed by an intramolecular Michael addition of the resulting stabilized carbanion on one of the $\alpha, \beta$ unsaturated ketones, and a final intramolecular oxa-Michael addition of the thermodynamic enolate intermediate. In addition to this, several chiral organocatalysts were evaluated to render this transformation enantioselective but only moderate enantioselectivities were obtained, with $(R, R)$-Takemoto's catalyst $\mathbf{4 2}$, performing at best, delivering the product in $58 \%$ ee. 

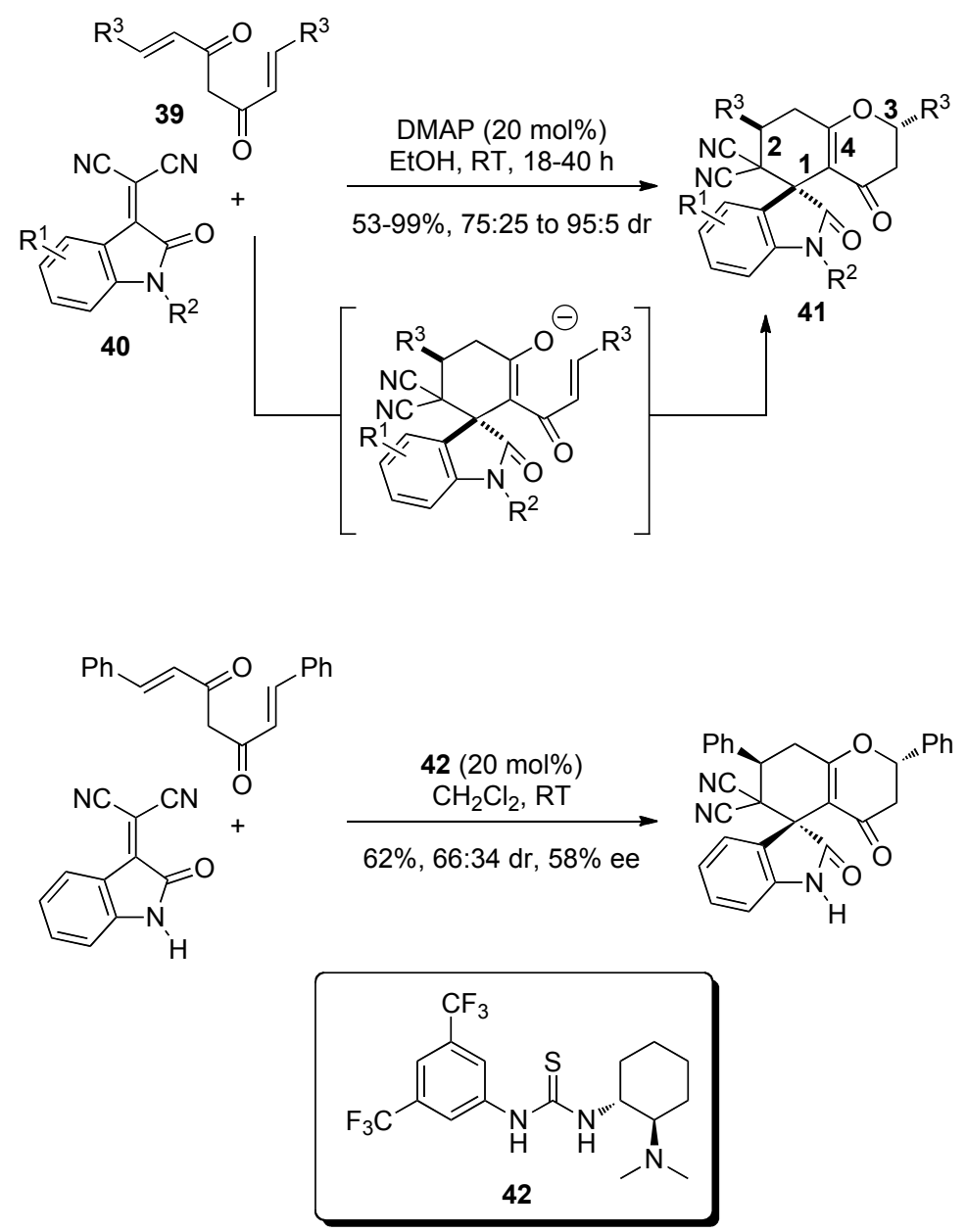

Scheme 12

\section{4 - CONCLUSION AND PERSPECTIVES}

This selection of sequential, domino and multicomponent reactions illustrates the high potential of 1,3-dicarbonyl derivatives for the synthesis of polycyclic heterocycles. These very easily accessible substrates can be accommodated in many synthetically efficient stereoselective multiple bond-forming transformations[36] in the racemic and optically active series. One of the main challenge in this field consists in further developments of new organocatalyzed MCRs based on the reactivity of 1,3-diCOs or taking advantages of the chemistry of their 1,2-analogues, that is less studied and still in its infancy.[37] 


\section{5 - ACKNOWLEDGEMENTS}

We thank all the former and current students from our research group who have contributed to the achievements reported in this article. Aix-Marseille Université, CNRS and French Ministry of Research are gratefully acknowledged for financial support.

\section{6 - REFERENCES AND NOTES}

[1] Tietze, L. F.; Brasche, G.; Gericke, K. M. Domino Reactions in Organic Synthesis; Wiley-VCH: Weinheim, 2006.

[2] (a) Multicomponent Reactions; Zhu, J.; Bienaymé, H., Eds; Wiley-VCH: Weinheim, 2005. (b) Climent, M. J.; Corma, A.; Iborra, S. Homogeneous and heterogeneous catalysts for multicomponent reactions. RSC $A d v$. 2012, 2, 16-58. (c) Dömling, A.; Wang, W.; Wang, K. Chemistry and Biology of Multicomponent Reactions. Chem. Rev. 2012, 112, 3083-3135. (d) Shiri, M. Indoles in Multicomponent Processes (MCPs). Chem. Rev. 2012, 112, 3508-3549.

[3] For some recent examples, see: (a) Powner, M. W.; Sutherland, J. D.; Szostak, J. W. Chemoselective Multicomponent One-Pot Assembly of Purine Precursors in Water. $J$. Am. Chem. Soc. 2010, 132, 16677-16688. (b) Powner, M. W.; Zheng, S.-L.; Szostak, J. W. Multicomponent Assembly of Proposed DNA Precursors in Water. J. Am. Chem. Soc. 2012, 134, 13889-13895. (c) Khalafi-Nezhad, A.; Sarikhani, S.; Shahidzadeh, E. S.; Panahi, F. L-Proline-promoted three-component reaction of anilines, aldehydes and barbituric acids/malononitrile: regioselective synthesis of 5-arylpyrimido[4,5b]quinoline-diones and 2-amino-4-arylquinoline-3-carbonitriles in water. Green Chem., 2012, 14, 2876-2884. 
[4] (a) Isambert, N.; Sanchez Duque, M. M.; Plaquevent, J.-C.; Génisson, Y.; Rodriguez, J.; Constantieux, T. Multicomponent reactions and ionic liquids: a perfect synergy for ecocompatible heterocyclic synthesis. Chem. Soc. Rev. 2011, 40, 1347-1357. (b) Gu, Y. Multicomponent reactions in unconventional solvents: state of the art. Green Chem. 2012, 14, 2091-2128.

[5] (a) Biggs-Houck, J. E.; Younai, A.; Shaw, J. T. Recent advances in multicomponent reactions for diversity-oriented synthesis. Curr. Opin. Chem. Biol. 2010, 14, 371-382. (b) Ruijter, E.; Scheffelaar, R.; Orru, R. V. A. Multicomponent Reaction Design in the Quest for Molecular Complexity and Diversity. Angew. Chem. Int. Ed. 2011, 50, 62346246.

[6] Jiang, B.; Rajale, T.; Wever, W.; Tu, S.-J.; Li, G. Multicomponent Reactions for the Synthesis of Heterocycles. Chem. Asian J. 2010, 5, 2318-2335.

[7] (a) Touré, B. B.; Hall, D. G. Natural Product Synthesis Using Multicomponent Reaction Strategies. Chem. Rev. 2009, 109, 4439-4486. (b) Nicolaou, K. C.; Chen, J. S. The art of total synthesis through cascade reactions. Chem. Soc. Rev. 2009, 38, 2993-3009. (c) Grondal, C.; Jeanty, M.; Enders, D. Organocatalytic cascade reactions as a new tool in total synthesis. Nature Chem. 2010, 2, 167-178.

[8] Domino reactions: (a) Enders, D.; Grondal, C.; Hüttl, M. R. M. Asymmetric Organocatalytic Domino Reactions. Angew. Chem. Int. Ed. 2007, 46, 1570-1581. (b) Alba, A.-N.; Companyo, X.; Viciano, M.; Rios, R. Organocatalytic Domino Reactions. Curr. Org. Chem. 2009, 13, 1432-1474. (c) Rios, R. Enantioselective methodologies for the synthesis of spiro compounds. Chem. Soc. Rev. 2012, 41, 1060-1074. (d) Bonne, D.; Constantieux, T.; Coquerel, Y.; Rodriguez, J. Asymmetric organocascades involving the formation of two C-heteroatom bonds from two distinct heteroatoms. Org. Biomol. Chem. 2012, 10, 3969-3973. Multicomponent reactions: (d) Ramón, D. J.; Yus, M. 
Asymmetric Multicomponent Reactions (AMCRs): The New Frontier. Angew. Chem. Int. Ed. 2005, 44, 1602-1634. (e) Guillena, G.; Ramón, D. J.; Yus, M. Organocatalytic enantioselective multicomponent reactions (OEMCRs). Tetrahedron: Asymmetry 2007, 18, 693-700. (f) van Berkel, S. S.; Bögels, B. G. M.; Wijdeven, M. A.; Westermann, B.; Rutjes, F. P. J. T. Recent Advances in Asymmetric Isocyanide-Based Multicomponent Reactions. Eur. J. Org. Chem. 2012, 3543-3559. (g) de Graaff, C.; Ruijter, E.; Orru, R. V. A. Recent developments in asymmetric multicomponent reactions. Chem. Soc. Rev. 2012, 41, 3969-4009. (h) Marson, C. M. Multicomponent and sequential organocatalytic reactions: diversity with atom-economy and enantiocontrol. Chem. Soc. Rev. 2012, 41, 7712-7722.

[9] (a) Constantieux, T.; Rodriguez, J. In Targets in Heterocyclic Systems; O. A. Attanasi and D. Spinelli, Eds.; Societe Chimica Italiana: Roma, 2005; Vol. 9, p 39-65. (b) Sanchez Duque, M. M.; Allais, C.; Isambert, N.; Constantieux, T.; Rodriguez, J. In Synthesis of Heterocycles via Multicomponent Reactions I. Top. Heterocycl. Chem. 2010, 23, 227-277.

[10] (a) Simon, C.; Constantieux, T.; Rodriguez, J. Utilisation of 1,3-Dicarbonyl Derivatives in Multicomponent Reactions. Eur. J. Org. Chem. 2004, 4957-4980. (b) Liéby-Muller, F.; Simon, C.; Constantieux, T.; Rodriguez, J. Current Developments in Michael Addition-Based Multicomponent Domino Reactions Involving 1,3-Dicarbonyls and Derivatives. QSAR Comb. Sci. 2006, 25, 432-438. (c) Bonne, D.; Coquerel, Y.; Constantieux, T.; Rodriguez, J. 1,3-Dicarbonyl compounds in stereoselective domino and multicomponent reactions. Tetrahedron: Asymmetry 2010, 21, 1085-1109.

[11] Jaisli, F.; Eschenmoser, A.; Shibuya, M. A Fragmentational Approach to Macrolides: (5-E,9-E)-6-methyl-5,9-undecadien-11-olide. Angew. Chem., Int. Ed. Engl. 1979, 18, 636-637. 
[12] Simon, C.; Peyronel, J.-F.; Rodriguez, J. A New Multicomponent Domino Reaction of 1,3-Dicarbonyl Compounds: One-Pot Access to Polycyclic N/O-, N/S-, and N/NAminals. Org. Lett. 2001, 3, 2145-2148.

[13] Noël, R.; Fargeau-Bellassoued, M.-C.; Vanucci-Bacqué, C.; Lhommet, G. Convenient One-Pot Synthesis of Chiral Tetrahydropyridines via a Multicomponent Reaction. Synthesis 2008, 1948-1954.

[14] Liéby-Muller, F.; Simon, C.; Imhof, K.; Constantieux, T.; Rodriguez, J. A Multicomponent Domino Reaction and in situ Aerobic Oxidation Sequence for the First One-Pot Synthesis of Polycyclic Benzimidazoles from 1,3-Dicarbonyl Derivatives. Synlett 2006, 1671-1674.

[15] Liéby-Muller, F.; Constantieux, T.; Rodriguez, J. Multicomponent Domino Reaction from $\beta$-Ketoamides: Highly Efficient Access to Original Polyfunctionalized 2,6Diazabicyclo[2.2.2]octane Cores. J. Am. Chem. Soc. 2005, 127, 17176-17177.

[16] El Asri, Z.; Génisson, Y.; Guillen, F.; Baslé, O.; Isambert, N.; Sanchez Duque, M. D. M.; Ladeira, S.; Rodriguez, J.; Constantieux, T.; Plaquevent, J.-C. Multicomponent reactions in ionic liquids: convenient and ecocompatible access to the 2,6-DABCO core. Green Chem. 2011, 13, 2549-2552.

[17] Liéby-Muller, F.; Constantieux, T.; Rodriguez, J. Highly Efficient Access to Original Polycyclic Pyrrolopiperazine Scaffolds by a Three-Component Reaction with 1,3Dicarbonyls. Synlett 2007, 1323-1325.

[18] Pilling, A. W.; Boehmer, J.; Dixon, D. J. Site-Isolated Base- and Acid-Mediated Michael-Initiated Cyclization Cascades. Angew. Chem. Int. Ed. 2007, 46, 5428-5430.

[19] Bensa, D.; Constantieux, T.; Rodriguez, J. P-BEMP: A New Efficient and Commercially Available User-Friendly and Recyclable Heterogeneous Organocatalyst for the Michael Addition of 1,3-Dicarbonyl Compounds. Synthesis, 2004, 923-927. 
[20] Pilling, A. W.; Bohmer, J.; Dixon, D. J. Site isolated base and acid catalyzed azaspirocyclization cascades. Chem. Commun. 2008, 832-834.

[21] Franzén, J.; Fisher, A. Asymmetric Alkaloid Synthesis: A One-Pot Organocatalytic Reaction to Quinolizidine Derivatives. Angew. Chem. Int. Ed. 2009, 48, 787-791.

[22] Zhang, W.; Franzén, J. Diverse Asymmetric Quinolizidine Synthesis: A Stereodivergent One-Pot Approach. Adv. Synth. Catal. 2010, 352, 499-518.

[23] Dai, X.; Wu, X.; Fang, H.; Nie, L.; Chen, J.; Deng, H.; Cao, W.; Zhao, G. Enantioselective organocatalyzed cascade reactions to highly functionalized quinolizidines. Tetrahedron 2011, 67, 3034-3040.

[24] Zhang, W.; Bah, J.; Wohlfarth, A.; Franzén, J. A Stereodivergent Strategy for the Preparation of Corynantheine and Ipecac Alkaloids, Their Epimers, and Analogues: Efficient Total Synthesis of (-)-Dihydrocorynantheol, (-)-Corynantheol, (-)Protoemetinol, (-)-Corynantheal, (-)-Protoemetine, and Related Natural and Nonnatural Compounds. Chem. Eur. J. 2011, 17, 13814-13824.

[25] Wu, X.; Dai, X.; Nie, L.; Fang, H.; Chen, J.; Ren, Z.; Cao, W.; Zhao, G. Organocatalyzed enantioselective one-pot three-component access to indoloquinolizidines by a Michael addition-Pictet-Spengler sequence. Chem. Commun. 2010, 46, 2733-2735.

[26] Rueping, M.; Volla, C. M. R. Bronsted-acid catalyzed condensation-Michael reactionPictet-Spengler cyclization-highly stereoselective synthesis of indoloquinolizidines. RSC Adv. 2011, 1, 79-82.

[27] Rueping, M.; Volla, C. M. R.; Bolte, M.; Raabe, G. General and Efficient Organocatalytic Synthesis of Indoloquinolizidines, Pyridoquinazolines and Quinazolinones through a One-Pot Domino Michael Addition-Cyclization- PictetSpengler or 1,2-Amine Addition Reaction. Adv. Synth. Catal. 2011, 353, 2853-2859. 
[28] Wu, X.; Fang, H.; Liu, Q.; Nie, L.; Chen, J.; Cao, W.; Zhao, G. Diastereoselective cascade reactions toward substituted diazaindeno[2,1- $\alpha]$ phenanthrenes. Tetrahedron 2011, 67, 7251-7257.

[29] Lin, S.; Deiana, L.; Tseggai, A.; Córdova, A. Concise Total Synthesis of Dihydrocorynanthenol, Protoemetinol, Protoemetine, 3-epi-Protoemetinol and Emetine. Eur. J. Org. Chem. 2012, 398-408.

[30] Jin, Z.; Wang, X.; Huang, H.; Liang, X.; Ye, J. Diastereo- and Enantioselective Synthesis of Oxazine and Oxazolidine Derivatives with a Chiral Quaternary Carbon Center under Multifunctional Catalysis. Org. Lett. 2011, 13, 564-567.

[31] Jin, Z.; Huang, H.; Li, W.; Luo, X.; Liang, X.; Ye, J. Enantioselective Organocatalytic Synthesis of Oxazolidine Derivatives through a One-Pot Cascade Reaction. Adv. Synth. Catal. 2011, 353, 343-348.

[32] Jin, Z.; Yu, F.; Wang, X.; Huang, H.; Luo, X.; Liang, X.; Ye, J. A one-pot asymmetric organocatalytic tandem reaction for the synthesis of oxazine derivatives. Org. Biomol. Chem. 2011, 9, 1809-1816.

[33] Islam, M. S.; Ishigami, K.; Watanabe, H. Synthesis of (-)-mellein, (+)-ramulosin, and related natural products. Tetrahedron 2007, 63, 1074-1079.

[34] (a) Ahmed, M. G.; Ahmed, S. A.; Uddin, M. K.; Rahman, M. T.; Romman, U. K. R.; Fujio, M.; Tsuda, Y. A facile synthesis of fused spiroketal skeleton: 2,2'-spirobi(4-aryl7,7-dimethyl-5-oxo-5,6,7,8-tetrahydrochroman). Tetrahedron Lett. 2005, 46, 82178220. (b) Agbaje, O. C.; Fadeyi, O. O.; Okoro, C. O. Lewis acid mediated diastereoselective synthesis of fused fluorinated spiroketal as potential biologically active compounds. Tetrahedron Lett. 2011, 52, 5297-5300. 
[35] Yin, X.-G.; Liu, X.-Y.; Hu, Z.-P.; Yan, M. Efficient synthesis of multicyclic spirooxindoles via a cascade Michael/Michael/oxa-Michael reaction of curcumins and isatylidene malononitriles. Org. Biomol. Chem. 2012, 10, 1506-150.

[36] Coquerel, Y.; Boddaert, T.; Presset, M.; Mailhol, D.; Rodriguez, J. Multiple bondforming transformations: the key Concept toward eco-compatible synthetic organic chemistry. In Ideas in Chemistry and Molecular Sciences: Advances in Synthetic Chemistry; Chap. 9, pp. 187-202; B. Pignataro, Ed.; Wiley-VCH: Weinheim, Germany, 2010.

[37](a) Raimondi, W.; Bonne, D.; Rodriguez, J. 1,2-Dicarbonyl compounds as pronucleophiles in organocatalytic asymmetric transformations. Angew. Chem. Int. Ed. 2012, 51, 40-42. (b) Raimondi, W.; Bonne, D.; Rodriguez, J. Asymmetric transformations involving 1,2-dicarbonyl compounds as pronucleophiles. Chem. Commun. 2012, 48, 6763-6775. 